\title{
Prevalence, awareness and risk factors of hypertension in Hmawbi Cantonment Area, Yangon Region, Myanmar
}

\author{
Ye Minn Htun ${ }^{1}$, Kyaw Sann Win' ${ }^{2}$, Ye Naung ${ }^{3}$, Wunna ${ }^{4}$, Kyaw Soe ${ }^{5}$
}

${ }^{1}$ Assistant Lecturer, Department of Research and Development; ${ }^{3}$ Senior Lecturer, Department of Research and Development; ${ }^{4}$ Head of Department of Research and Development and Second in Command; ${ }^{5}$ Professor and Head, Department of Preventive and Social Medicine, Defence Services Medical Academy and Commanding Officer of Defence Services Medical School, Hmawbi, Yangon, Myanmar. ${ }^{2}$ Assistant Lecturer, Department of Preventive and Social Medicine, Defence Services Medical Academy, Mingladon, Yangon, Myanmar.

\begin{abstract}
Hypertension is one of the leading risk factors for global mortality. A community based cross sectional descriptive study was conducted in Hmawbi Cantonment Area, Yangon Region in November, 2015. This study aimed to identify the prevalence, awareness and risk factors of hypertension concerning smoking, alcohol dinking, eating food pattern, taking regular exercise, stressful condition and body mass index (BMI). The sample consisted of 210 respondents from three Units (Light Infantry Regiments) were randomly selected to participate in the study. A pre-tested structured questionnaire was used as a data collection tool. It was found that 33.3\% of respondents had hypertension; $55.7 \%$ achieved good awareness on hypertension as well; $16.7 \%$ respondents were current smoker; $7.6 \%$ had the history of alcohol drinking; $67.1 \%$ respondents took regular exercise; $29.5 \%$ respondents were in stressful condition; $32.9 \%$ respondents were overweight and $19.5 \%$ were obese. Hypertension was significantly associated with age $(p-0.001)$, family income $(p<0.001)$, awareness level $(p-0.01)$, current smoking status $(p<0.001)$, alcohol drinking $(p<0.001)$, regular exercise taking $(p<0.001)$, stressful condition $(p<0.001)$, and increase BMI $(p<0.001)$ of respondents. This setting in Hmawbi evidenced that age, family income, smoking, alcohol drinking, consumption of salty and fast food, stressful condition and increase BMI were identified as risk factors and taking regular exercise was protective. Overall, over $50 \%$ of respondents having good awareness show that favorable circumstances exist for further strengthening the hypertension prevention and control program. These findings have implications for future public health intervention and clinical efforts to decrease the prevalence of hypertension among population.
\end{abstract}

Keywords: Prevalence, Awareness, Risk factors, Hypertension, Myanmar.

\section{Introduction}

Hypertension is one of the important public health problems worldwide because its disease burden is getting higher in both developed and developing countries. ${ }^{1}$ It is also one of the most important contributors to heart disease and stroke - which together make up the world's number one cause of premature death and disability. ${ }^{2}$ Globally, the overall prevalence of hypertension among adults population aged from 18 and over was around $22 \%$ in 2014. ${ }^{3}$ This contributes nearly 9.4 million deaths from cardiovascular disease each year, it is growing epidemic and is estimated to affect more than one in three adults aged 25 and over, or about one billion people. ${ }^{2}$

The specific underlying cause of hypertension cannot be found in patients who are said to have essential hypertension. Many factors may contribute to its development, including renal dysfunction, peripheral resistance vessel tone, endothelial dysfunction, autonomic tone, insulin resistance and neurohumoral factors. Hypertension is more common in some ethnic groups, particularly African Americans and Japanese, and approximately 40$60 \%$ is explained by genetic factors. ${ }^{4}$

Essential hypertension is related to heredity, old age, male sex in young and middle-aged adults, Black Afro-American ethnicity, low socioeconomic status in

\section{Practice Points}

- Hypertension is one of the leading risk factors for global morbidity and mortality.

- More than one-third of respondents were hypertensive and among them, 44.3\% had pre-hypertension, $38.6 \%$ were hypertension stage I and $17.1 \%$ were state II.

- In socio-demographic factors, age group (40-60 years) and family income group (250000500000 kyats) were found to be significantly associated with hypertension.

- Smoking, alcohol drinking, dietary habits, irregular exercise, overweight and stressful condition were also significantly associated with hypertension.

- National Non-communicable Disease Strategic Plan should be implemented through a primary health care approach as an affordable and sustainable way; required provision to reduce the exposure of the whole population to risk factors of hypertension.

Correspondence: Dr. Ye Minn Htun, Assistant Lecturer, Room No 8, Officer Hostel, Defence Services Medical School, Hmawbi, Yangon 11111, Myanmar. Email: dryeminnhtun85@gmail.com. 
developed economies and high socioeconomic status in transitional economies, obesity, alcohol consumption, physical inactivity, high salt intake, hormonal contraceptives, and stress. ${ }^{5}$ Important environmental factors include a high salt intake, heavy consumption of alcohol, obesity, lack of exercise and impaired intrauterine growth. There is little evidence that 'stress' causes hypertension. ${ }^{6}$

The treatment of hypertension has been shown to prevent cardiovascular diseases and to extend and enhance life, hypertension remains inadequately managed everywhere. Different national and international organizations have defined the concept of 'hypertension' and also divided the disease into degrees of severity based on a number of large epidemiological and treatment studies.

The prevalence of hypertension is highest in Africa (46\% of adults) while the lowest prevalence is found in the Americas (35\% of adults). Overall, high-income countries have a lower prevalence of hypertension $(35 \%$ of adults) than low and middle income groups $(40 \%$ of adults). ${ }^{2}$ Almost half of the disease burden in low and middle income countries is now caused by noncommunicable diseases, especially stroke and ischemic heart disease. ${ }^{8}$ The risk of cardiovascular disease doubles for every 10 points increase in diastolic blood pressure or every 20 points increase in systolic blood pressure. ${ }^{9}$ About two thirds of stroke and half of ischemic heart disease were attributable to high blood pressure globally. It also increases the risk of conditions such as kidney failure and blindness. ${ }^{2}$

The incidence is also increasing in most countries and lifestyle factors are considered to play a decisive role in this development. Obesity, physical inactivity and increased salt intake, in particular, have varying degrees of significance in different populations. As a single risk factor, physical inactivity is believed to be responsible for $5-13 \%$ of hypertension today. ${ }^{7}$

In the South-East Asia Region, approximately 35\% of the adult population has hypertension, which accounts for nearly 1.5 million deaths annually; $9.4 \%$ of the total deaths are attributable to hypertension. ${ }^{10}$ The four major behavioral risk factors of non-communicable diseases (tobacco use, unhealthy diet, lack of physical activity and harmful use of alcohol) that lead to four major metabolic risk factors (overweight/obesity, hypertension, raised blood sugar and raised blood lipids) are highly prevalent in the region and on the rise. ${ }^{5}$

Detecting high blood pressure is the first step in preventing and controlling it. When people know their blood pressure level, they can take steps to control it. People can cut the risks of high blood pressure by: consuming less salt, eating a balanced diet, engaging in regular physical activity, avoiding tobacco use and avoiding harmful use of alcohol. ${ }^{11}$

The purpose of this study is to estimate the prevalence and, determine the awareness and associated risk factors of hypertension among the adult population in Hmawbi Cantonment Area, Yangon Region. This information is important to provide and support strategic decisions such as public health interventions to reduce risk factors and decrease the burden of disease.

\section{Materials and methods}

\section{Sampling method and procedure}

The study was conducted as a community-based crosssectional descriptive study and carried out at Hmawbi Cantonment Area, Yangon Region, Myanmar, in November 2015.

The study population was military community and sample size was determined based on a study conducted in Myanmar. ${ }^{12}$ Among 23 regiments, three were selected for the study by simple random sampling. Seventy respondents were selected from each of these three regiments using simple random sampling procedure. List of over 35 years age people for sampling frame was accessible from the adjutant of each regiment.

\section{Data collection method and tools}

Before the main data collection, quantitative data were collected by face to face interview method using pre-tested structured questionnaires. Then the questionnaires were modified according to pretest results. The study population was explained about the purpose of the study and was requested for participation in the study. Then the face to face interviews were conducted at three regiments after receiving informed consent.

The questionnaire comprised 53 questions, divided into 3 parts. First part included socio-demographic factors such as gender, age, educational status, marital status, family income of respondents. Second part included 11 questions for awareness of hypertension and third part included risk factors related questions. Scoring for the awareness questions were 1 and 0 ( 1 for correct answer and 0 for incorrect and don't know answers).

Blood pressure was measured with the standard mercury sphygmomanometer in good working condition after standardization. The respondents were asked to avoid physical exertion, smoking, coffee drinking etc. and then rest for 5 minutes. After removing clothes from the arm, in sitting position, one inch above the elbow of right upper arm, systolic blood pressure was taken at Korotcoff first sound and diastolic blood pressure at phase five.

Weight measurement was done by portable bathroom weight measuring scale in even and hard surface. The respondents were in light clothes without foot wearing. By height measuring tape showing both Metric and British system of length in standing position, optimal exposure against a vertical surface with the head position so that top of the external auditory meatus was in level with the inferior margin of the bony orbit.

\section{Data management and analysis}

Collected data were reviewed for completeness and relevancy, and then data entry was done with SPSS 16.0 (Statistical Package for Social Sciences) software program. The data were checked for completeness, error and inconsistency after data collection. Data were cleaned by checking for errors and outliers. Data summarization was done by presenting tables, and measures of central tendency and measures of dispersion were also calculated. Cross tabulation was done for testing of significance for association between categorical variables, using Chi-square test. The statistical level of significance was $p \leq 0.05$. 


\section{Ethical consideration}

Ethical clearance was obtained from Ethical Board of Studies, Defense Services Medical School.

\section{Results}

The socio-demographic characteristics of study population are shown in Table 1. Most of respondents were females $82.9 \%$; in the age range of $40-60$ years $62.4 \%$; Bamar $84.3 \%$; middle school education level $38.6 \%$; dependents $82.8 \%$; and had less than 250000 kyats of family income $64.8 \%$.

Table 2 revealed the distribution of risk factors among respondents. It can be found that $16.7 \%$ respondents were current smokers and $71.4 \%$ of them had history of daily smoking. In alcohol drinking, $7.6 \%$ of respondents were current drinker and $87.5 \%$ of these current drinkers gave the history of drinking previous 12 months. Most of the respondents sometime ate fish source, fish prawn salt, fishy juice $55.2 \%$, saturated oil $51.4 \%$, monosodium glutamate $61.9 \%$, fast food $52.9 \%$ and transfat $55.2 \%$. It was also observed that $67.1 \%$ of the respondents took regular exercise and $78.1 \%$ of them took 30 minutes and more per day. Regarding the

Table 1: Distribution of socio-demographic characteristics among respondents $(n=210)$

\begin{tabular}{|c|c|}
\hline $\begin{array}{c}\begin{array}{c}\text { Socio-demographic } \\
\text { characteristics }\end{array} \\
\end{array}$ & Respondents (\%) \\
\hline \multicolumn{2}{|l|}{ Gender } \\
\hline Male & $36(17.1 \%)$ \\
\hline Female & $174(82.9 \%)$ \\
\hline \multicolumn{2}{|l|}{ Age (year) } \\
\hline$\leq 40$ years & $69(32.9 \%)$ \\
\hline $40-60$ years & $131(62.4 \%)$ \\
\hline$>60$ years & $10(4.8 \%)$ \\
\hline \multicolumn{2}{|c|}{ Mean \pm SD: $(44.98 \pm 10.89)$; range: $35-74$ years } \\
\hline \multicolumn{2}{|c|}{ Race } \\
\hline Bamar & $177(84.3 \%)$ \\
\hline Shan & $9(4.3 \%)$ \\
\hline Kayin & $10(4.8 \%)$ \\
\hline Rakhine & $12(5.7 \%)$ \\
\hline Mon & $2(1.0 \%)$ \\
\hline \multicolumn{2}{|l|}{ Education } \\
\hline Illiterate & $10(4.8 \%)$ \\
\hline Read and write & $15(7.1 \%)$ \\
\hline Primary & $59(28.1 \%)$ \\
\hline Middle & $81(38.6 \%)$ \\
\hline High & $41(19.5 \%)$ \\
\hline Graduate & $4(1.9 \%)$ \\
\hline \multicolumn{2}{|l|}{ Rank } \\
\hline Lance Corporal & $5(2.3 \%)$ \\
\hline Corporal & $11(5.2 \%)$ \\
\hline Sergeant & $9(4.3 \%)$ \\
\hline Warrant Officer II & $7(3.3 \%)$ \\
\hline Warrant Officer I & $4(1.9 \%)$ \\
\hline \multicolumn{2}{|l|}{ Dependency } \\
\hline Dependent & $174(82.8 \%)$ \\
\hline \multicolumn{2}{|l|}{ Family Income } \\
\hline$<250000$ kyats & $136(64.8 \%)$ \\
\hline $250000-500000$ kyats & $74(35.2 \%)$ \\
\hline \multicolumn{2}{|c|}{$\begin{array}{l}\text { Mean } \pm \text { SD: }(250000 \pm 89000) \\
\text { Range: } 120000-500000 \text { kyats }\end{array}$} \\
\hline
\end{tabular}

body mass index (BMI) of respondents, $47.6 \%$ were within normal range, $32.9 \%$ respondents were overweight and $19.5 \%$ were obese. There were $70.5 \%$ respondents with no stress and $29.5 \%$ respondents with stress.

As shown in Table 3, 44.3\% respondents had poor awareness and $55.7 \%$ had good awareness. Regarding the prevalence of hypertension, $33.3 \%$ respondents were hypertensive. Among them, 44.3\% respondents were pre-hypertension, $38.6 \%$ were hypertension stage I and $17.1 \%$ were hypertension state II.

Table 4 shows the association between the sociodemographic characteristics, awareness, risk factors of respondents and prevalence of hypertension. Concerning socio-economic characteristics, 40-60 years age group and 250000-500000 kyat family income group are found to be statistically significantly associated with hypertension. It can be assumed that female respondents were found to have hypertension more but their association was not statistically significant. Similarly, other races were found to catch hypertension than the Bamar respondents. However, their association was not statistically significant.

It was also observed that respondents who had poor awareness $41.9 \%$ were found to get hypertension than the respondents who had good awareness $26.5 \%$ and was significantly associated with hypertension. Regarding to the risk factors, hypertension had significant association with current smokers $(p<0.001)$, alcohol drinkers $(p<0.001)$, various salty and fast food patterns $(p-0.01)$ such as consumption of fish, fish prawn salt, fishy juice, use of saturated oil, $(p<0.01)$, use of monosodium glutamate during cooking $(p<0.001)$, use of fast food $(p<0.001)$, and use of transfat $(p-0.001)$. Moreover, hypertension was significantly associated with irregular exercise $(p<0.001)$, stressful condition $(p<0.001)$ and overweight respondents $(p<0.001)$.

\section{Discussion}

Awareness of hypertension among military persons and their families is vital for success of hypertension prevention and control program. The cross-sectional descriptive study of prevalence, awareness and risk factors of hypertension in military community was carried out to find out major modifiable risk factors of hypertension, and the association between these factors and prevalence of hypertension.

In this study, we found that the prevalence of the respondents was $33.3 \%$ and it was lower than the previous studies conducted in Bangladesh and India $65 \%,{ }^{13}$ among the aboriginal Nicobarese tribe living in Car Nicobar Island, India $50.5 \%,{ }^{14}$ in Iranian adult population $41.8 \% .{ }^{15}$ However, the prevalence of other studies conducted in India $29.3 \%{ }^{16}$, in the northwestern tip of Penang Island, Malaysia 29.8\%, ${ }^{17}$ in middle Anatolian city $24.2 \%{ }^{18}$ and in Jalalabad City, Nangarhar Province, Afghanistan $28.4 \%{ }^{19}$ were lower than that of current study.

Regarding the awareness on hypertension, there were $55.7 \%$ respondents with good awareness which is higher than the findings $33.96 \%$ respondents with 
Table 2: Distribution of risk factors among respondents

\begin{tabular}{|c|c|c|c|}
\hline \multicolumn{3}{|c|}{ Risk factors } & Respondents (\%) \\
\hline \multirow{6}{*}{ Smoking } & \multirow{2}{*}{ Currently smoking $(\mathrm{n}=210)$} & Yes & $35(16.7 \%)$ \\
\hline & & No & $175(83.3 \%)$ \\
\hline & \multirow{2}{*}{ Daily smoking $(\mathrm{n}=35)$} & Yes & $25(71.4 \%)$ \\
\hline & & No & $10(28.6 \%)$ \\
\hline & \multirow{2}{*}{ Previously smoking $(\mathrm{n}=175)$} & Yes & $12(6.9 \%)$ \\
\hline & & No & $163(93.1 \%)$ \\
\hline \multirow{4}{*}{ Alcohol drinking } & \multirow{2}{*}{ Current drinking $(\mathrm{n}=210)$} & Yes & $16(7.6 \%)$ \\
\hline & & No & $194(92.4 \%)$ \\
\hline & \multirow{2}{*}{$\begin{array}{l}\text { Drinking within previous } 12 \text { months } \\
(\mathrm{n}=16)\end{array}$} & Yes & $14(87.5 \%)$ \\
\hline & & No & $2(12.5 \%)$ \\
\hline \multirow{15}{*}{ Food pattern } & \multirow{3}{*}{$\begin{array}{l}\text { Taking with Fish source, Fish prawn } \\
\text { salt, Fishy juice }(n=210)\end{array}$} & Daily & $73(34.8 \%)$ \\
\hline & & Sometime & $116(55.2 \%)$ \\
\hline & & Never & $21(10.0 \%)$ \\
\hline & \multirow{3}{*}{ Usage of saturated oil $(n=210)$} & Daily & $38(18.1 \%)$ \\
\hline & & Sometime & $108(51.4 \%)$ \\
\hline & & Never & $64(30.5 \%)$ \\
\hline & \multirow{3}{*}{$\begin{array}{l}\text { Usage of Monosodium glutamate at } \\
\text { cooking }(n=210)\end{array}$} & Daily & $31(14.8 \%)$ \\
\hline & & Sometime & $116(55.2 \%)$ \\
\hline & & Never & $63(30.0 \%)$ \\
\hline & \multirow{3}{*}{ Usage of fast food $(n=210)$} & Daily & $42(20.0 \%)$ \\
\hline & & Sometime & $111(52.9 \%)$ \\
\hline & & Never & $57(27.1 \%)$ \\
\hline & \multirow{3}{*}{ Usage of trans-fat $(n=210)$} & Daily & $7(3.3 \%)$ \\
\hline & & Sometime & $130(61.9 \%)$ \\
\hline & & Never & $73(34.8 \%)$ \\
\hline \multirow{4}{*}{ Exercise } & \multirow{2}{*}{ Taking regular exercise $(n=210)$} & Yes & $141(67.1 \%)$ \\
\hline & & No & $69(32.9 \%)$ \\
\hline & \multirow{2}{*}{$\begin{array}{l}\text { Duration of regular exercise in each day } \\
(\mathrm{n}=141)\end{array}$} & $<30$ min & $31(21.9 \%)$ \\
\hline & & $\geq 30 \mathrm{~min}$ & $110(78.1 \%)$ \\
\hline \multirow{3}{*}{ Body Mass Index } & \multicolumn{2}{|l|}{ Normal weight } & $100(47.6 \%)$ \\
\hline & \multicolumn{2}{|l|}{ Overweight } & $69(32.9 \%)$ \\
\hline & \multicolumn{2}{|l|}{ Obese } & $41(19.5 \%)$ \\
\hline \multirow{3}{*}{ Stress } & \multicolumn{2}{|l|}{ No stress $(<$ mean score $)$} & $148(70.5 \%)$ \\
\hline & \multicolumn{2}{|l|}{ Stressful ( $\geq$ mean score) } & $62(29.5 \%)$ \\
\hline & Mean score (SD; Range): 1.0 & $0-8)$ & \\
\hline
\end{tabular}

Table 3: Awareness and prevalence of hypertension among respondents

\begin{tabular}{|l|l|c|}
\hline \multicolumn{1}{|c|}{ Factors } & \multicolumn{1}{c|}{ Respondents (\%) } \\
\hline \multirow{3}{*}{ Awareness (n=210) } & Poor (<mean score) & $93(44.3 \%)$ \\
\cline { 2 - 3 } & Good ( $\geq$ mean score) & $117(55.7 \%)$ \\
\cline { 2 - 3 } & Mean score (SD; Range) $-20.03(2.98 ; 12-27)$ \\
\hline \multirow{4}{*}{ Hypertension (n=210) } & Yes & $70(33.3 \%)$ \\
\cline { 2 - 3 } & \multicolumn{1}{|c|}{ Pre hypertension (n=70) } & $31(44.3 \%)$ \\
\cline { 2 - 3 } & Hypertension stage I (n=70) & $27(38.6 \%)$ \\
\cline { 2 - 3 } & No & $12(17.1 \%)$ \\
\hline
\end{tabular}

good awareness of a previous study conducted in Myanmar among the middle aged people in Bago Township, ${ }^{21} 44.7 \%$ of awareness in study of Bangladesh and India ${ }^{13}$, and $46.2 \%$ of awareness in study of Iranian adult population. ${ }^{15}$

In the association between socio-demographic characteristics and hypertension, hypertension was statistically significant associated with ages groups ( $p$ $0.001)$, and level of family income $(p<0.001)$ of respondents. In the study of Aung et al. ${ }^{20}$ study, hypertension was also statistically significant associated with age groups and family income level. It indicated that prevalence of hypertension increased with increasing age and family income level. Kyaw et $a .^{21}$ revealed that hypertension was also statistically significant associated with age and family income. However, hypertension was not statistically significant associated with gender and race of respondents in our study. Doğan et al. ${ }^{18}$ stated that significant risk factors of hypertension were age $(p<0.0001)$, gender $(p<0.0001)$ and income $(p<0.0001)$. The study conducted in Jalalabad City, Nangarhar Province, Afghanistan

South East Asia Journal of Public Health 2016;6(1):20-26 
Table 4: Association between socio-demographic characteristics, awareness, risk factors of respondents and prevalence of hypertension $(\mathrm{n}=210)$

\begin{tabular}{|c|c|c|c|c|}
\hline \multirow[b]{2}{*}{ Variable } & \multicolumn{3}{|c|}{ Hypertension } & \multirow[b]{2}{*}{$p$ value } \\
\hline & $\begin{array}{c}\text { Present } \\
\text { Respondents (\%) }\end{array}$ & $\begin{array}{c}\text { Absent } \\
\text { Respondents (\%) }\end{array}$ & $\begin{array}{c}\text { Total } \\
\text { Respondents }\end{array}$ & \\
\hline \multicolumn{5}{|l|}{ Gender } \\
\hline Men & $8(22.2 \%)$ & $28(77.8 \%)$ & 36 & \multirow{2}{*}{0.12} \\
\hline Women & $62(35.6 \%)$ & $112(64.4 \%)$ & 174 & \\
\hline \multicolumn{5}{|l|}{ Age (year) } \\
\hline$<40$ & $11(15.9 \%)$ & $58(84.1 \%)$ & 69 & \multirow{3}{*}{0.001} \\
\hline $40-60$ & $55(42.0 \%)$ & $76(58.0 \%)$ & 131 & \\
\hline$>60$ & $4(40.0 \%)$ & $6(60.0 \%)$ & 10 & \\
\hline \multicolumn{5}{|l|}{ Race } \\
\hline Bamar & $57(32.2 \%)$ & $120(67.8 \%)$ & 177 & \multirow{2}{*}{0.42} \\
\hline Others & $13(39.4 \%)$ & $20(60.6 \%)$ & 33 & \\
\hline \multicolumn{5}{|l|}{ Family Income } \\
\hline$<250000$ kyat & $33(24.3 \%)$ & $103(75.7 \%)$ & 136 & \multirow{2}{*}{$<0.001$} \\
\hline $250000-500000$ kyat & $37(50.0 \%)$ & $37(50.0 \%)$ & 74 & \\
\hline \multicolumn{5}{|l|}{ Awareness } \\
\hline Poor & $39(41.9 \%)$ & $54(58.1 \%)$ & 93 & \multirow{2}{*}{0.01} \\
\hline Good & $31(26.5 \%)$ & $86(73.5 \%)$ & 117 & \\
\hline \multicolumn{5}{|l|}{ Risk factors } \\
\hline \multicolumn{5}{|l|}{ Current Smoking } \\
\hline Yes & $33(94.3 \%)$ & $2(5.7 \%)$ & 35 & \multirow{2}{*}{$<0.001$} \\
\hline No & $37(21.1 \%)$ & $138(78.9 \%)$ & 175 & \\
\hline \multicolumn{5}{|l|}{ Alcohol Drinking } \\
\hline Yes & $16(100.0 \%)$ & 0 & 16 & \multirow{2}{*}{$<0.001$} \\
\hline No & $54(27.8 \%)$ & $140(72.2 \%)$ & 194 & \\
\hline \multicolumn{5}{|l|}{ Food patterns } \\
\hline Taking with fish sourc & awn salt, fishy juice & & & \\
\hline Daily & $33(45.2 \%)$ & $40(54.8 \%)$ & 73 & \\
\hline Sometime & $34(29.3 \%)$ & $82(70.7 \%)$ & 116 & 0.01 \\
\hline Never & $3(14.3 \%)$ & $18(85.7 \%)$ & 21 & \\
\hline Usage of saturated oil & & & & \\
\hline Daily & $18(47.4 \%)$ & $20(52.6 \%)$ & 38 & \\
\hline Sometime & $43(39.8 \%)$ & $65(60.2 \%)$ & 108 & $<0.001$ \\
\hline Never & $9(14.1 \%)$ & $55(85.9 \%)$ & 64 & \\
\hline Usage of Monosodium & te at cooking & & & \\
\hline Daily & $14(45.2 \%)$ & $17(54.8 \%)$ & 31 & \\
\hline Sometime & $45(38.8 \%)$ & $71(61.2 \%)$ & 116 & $<0.01$ \\
\hline Never & $11(17.5 \%)$ & $52(82.5 \%)$ & 63 & \\
\hline Usage of fast food & & & & \\
\hline Daily & $29(69.0 \%)$ & $13(31.0 \%)$ & 42 & \\
\hline Sometime & $34(30.6 \%)$ & $77(69.4 \%)$ & 111 & $<0.001$ \\
\hline Never & $7(12.3 \%)$ & $50(87.7 \%)$ & 57 & \\
\hline Usage of trans-fat & & & & \\
\hline Daily & $5(71.4 \%)$ & $2(28.6 \%)$ & 7 & \\
\hline Sometime & $51(39.2 \%)$ & $79(60.8 \%)$ & 130 & 0.001 \\
\hline Never & $14(19.2 \%)$ & $59(80.8 \%)$ & 73 & \\
\hline Regular Exercise & & & & \\
\hline No & $53(76.8 \%)$ & $16(23.2 \%)$ & 69 & $<0001$ \\
\hline Yes & $17(12.1 \%)$ & $124(87.9 \%)$ & 141 & $<0.001$ \\
\hline Stress & & & & \\
\hline Stressful & $36(58.1 \%)$ & $26(41.9 \%)$ & 62 & \\
\hline No Stress & $34(23.0 \%)$ & $114(77.0 \%)$ & 148 & $<0.001$ \\
\hline Body Mass Index & & & & \\
\hline Normal weight & $20(20.0 \%)$ & $80(80.0 \%)$ & 100 & \\
\hline Overweight & $36(52.2 \%)$ & $33(47.8 \%)$ & 69 & $<0.001$ \\
\hline Obese & $14(34.1 \%)$ & $27(65.9 \%)$ & 41 & \\
\hline
\end{tabular}

South East Asia Journal of Public Health 2016;6(1):20-26 
showed that hypertension was significantly associated with gender and level of income. ${ }^{19}$ Hypertension was also significant associated with gender and age in the study of Malekzadeh et al. ${ }^{15}$ The study conducted among urban adult population in India also showed hypertension was also statistically significant associated with age, sex and education. ${ }^{16}$ The associations between hypertension and various age, and education subcategories were statistically significant $(p<0.05)$ in the study of Manimunda et al. ${ }^{14}$ In Malaysia study, age group and education level were also found to be statistically significant with hypertension. ${ }^{17}$ It demonstrated that respondents with the highest educational level and young age group had the lowest prevalence of hypertension.

Regarding the awareness of hypertension, respondents with poor awareness (41.9\%) had hypertension more than respondents with good awareness (26.5\%). There was statistically significant association between awareness and hypertension $(p-0.01)$. It demonstrated that poor awareness could increase the prevalence of hypertension among population. Iranian adult population study stated that awareness of being hypertensive was significantly higher in women and it was also more common in older patients, overweight and obese patients, urban residents, illiterates, those with less physical activity and never-smokers. ${ }^{15}$ In the study of Zafar et al., ${ }^{22}$ there were significantly different of awareness between hypertensive respondents and normotensive respondents. In the study conducted in Bangladesh and India, there were also significantly associated between hypertension and awareness. ${ }^{13}$

In this study, hypertension was significant associated with current smokers, alcohol drinkers, various salty and fast food patterns such as consumption of fish, fish prawn salt, fishy juice, use of saturated oil, use of monosodium glutamate during cooking, use of fast food, and use of transfat. Moreover, hypertension was significantly associated with irregular exercise, stressful condition and overweight respondents. Thus, most of risk factors were associated with hypertension in the present study.

The study conducted in Bago Township revealed that hypertension was also associated with smoking $(p<0.001)$, alcohol drinking $(p<0.001)$, physical exercise $(p<0.001)$ and body mass index $(p<0.001)$. Nevertheless, there were no association between hypertension and dietary patterns, and stress. ${ }^{21}$ In the study of Aung, ${ }^{20}$ hypertension was statistically significant associated with alcohol drinking $(p<0.001)$, salt consumption status $(p<0.001)$, physical activity $(p<0.001)$, stressful condition $(p<0.001)$ and body mass index $(p<0.001)$. However, there was no statistically significant association between smoking status and hypertension condition.

In a study conducted by Doğan et al. ${ }^{18}$ in Turkey, it was demonstrated that significant risk factors of hypertension were obesity $(p<0.0001)$. Another study from Afghanistan showed that hypertension was significantly associated with obesity, and physical activity. ${ }^{19}$ Hypertension was also significant associated with BMI and physical activity at work in the study of Malekzadeh et. al. ${ }^{15}$ The study conducted among urban adult population in India showed that hypertension was also statistically significant associated with extra salt intake, current smoker, current alcoholic, high body mass index, and physical inactivity. ${ }^{16}$ The associations between hypertension and alcohol consumption status, and overweight/obesity were statistically significant $(p<0.05)$ in the study of Manimunda et al. ${ }^{14}$ In Malaysia study, alcohol consumption and body mass index were found to be statistically significant with hypertension. ${ }^{17}$

In this study, major risk factors were asked to the respondents by cross sectional descriptive method. More detail risk factors will be explored by case control study. One limitation in this study is that blood pressure has been checked two times within a period of 30 minutes according to the researcher as well as respondents, which should have been confirmed on further follow up. Another limitation is that the study was intended for essential hypertension, secondary hypertension could not be excluded. The next one is that most of military persons were away from their regiments for training at the time of data collection.

\section{Conclusion}

Myanmar is now facing double burden of diseases communicable diseases and non-communicable diseases. Hypertension is one of the important health problems and the priority actions are needed to develop with the aim to prevent, control and reduce disease, disability and premature deaths from hypertension. The risk factors of hypertension such as smoking, alcohol drinking, consumption of salty and fast food, sedentary life style, stress condition and increase body mass index will be diminished by improving the awareness and changing the lifestyle of population.

Based on these findings, population should be educated on the risk factors, presenting features and complications of hypertension by implementing National Non-communicable Disease Strategic Plan in order to reduce the risk factors of hypertension. Provision of this plan would further enhance awareness of hypertension and would gradually decrease the prevalence of hypertension among population.

\section{Competing interest}

The authors declare that they have no competing interests.

\section{References}

1. Kearney PM, Whelton M, Reynolds K, Muntner $\mathrm{P}$, Whelton $\mathrm{PK}, \mathrm{He} \mathrm{J}$. Global burden of hypertension: analysis of worldwide data. Lancet 2005; 365(9455):217-23.

2. World Health Organization. Hypertension, Media Centre, World Health Day 2013: Measure your blood pressure; reduce your risk. http:// www.who.int/mediacentre/news/releases/2013/ world health_day_20130403/en// (accessed June 2016).

3. World Health Organization. Global Health Observatory (GHO) Data. http://www.who.int/ $\mathrm{gho} / \mathrm{ncd} / \mathrm{risk}$ factors/blood pressure text/en// (accessed June 2016).

4. World Health Organization. WHO/International 
Society of Hypertension guidelines. http:// www.who.int/cardiovascular_diseases guidelines/hypertension/en/ (accessed June 2016).

5. World Health Organization. Non-communicable Diseases in the South-East Asia Region, Situation and Response. New Delhi: World Health Organization, Regional Office for SouthEast Asia, 2011.

6. Brian RW, Nicki RC. Davidson's Principle and Practice of Medicine. $22^{\text {nd }}$ edition. London: Churchill Livingstone, 2014.

7. Börjesson M, Kjeldsen S, Dahlöf B. Physical Activity in the Prevention and Treatment of Disease. 2nd ed. Östersund: Professional Associations for Physical Activity, 2010.

8. Lopez AD, Mathers CD, Ezzati M, Jamison DT, Murray CJ. Global and regional burden of disease and risk factors, 2001: Systematic analysis of population health data. Lancet 2006; 367(9524):1747-57.

9. Mackay J, Mensah GA, Mendis S, Greenlund K. The atlas of heart disease and stroke. Geneva: World Health Organization, 2004.

10. Krishnan A, Garg R, Kahandaliyanage A. Hypertension in the South-East Asia region: an overview. Special Issue on blood pressure Take control. Region Health Forum 2013;17(1):7 -14 .

11. World Health Organization. Hypertension. Health Topics. http://www.who.int/topics/ hypertension/en/ (accessed June 2016).

12. Win ZY. Risk factors and awareness regarding hypertension among hypertension patients attending hypertension clinic at No (2) military hospital (500 bedded). [thesis]. Master of Public Health. Defence Services Medical Academy, Mingladon, Myanmar, 2009.

13. Hypertension Study Group. Prevalence, awareness, treatment and control of hypertension among the elderly in Bangladesh and India: a multicentre study. Bull World Health Org 2001; 79(6):490-500.
14. Manimunda SP, Sugunan AP, Benegal V, Balakrishna N, Rao MV, Pesala KS. Association of hypertension with risk factors \& hypertension related behaviour among the aboriginal Nicobarese tribe living in Car Nicobar Island, India. Indian J Med Res 2011; 133(3):287-93.

15. Malekzadeh MM, Etemadi A, Kamangar F, Khademi H, Golozar A, Islami F, et al. Prevalence, awareness and risk factors of hypertension in a large cohort of Iranian adult population. Jhypertension. 2013;31(7):1364-71.

16. Prabakaran J, Vijayalakshmi N, Venkata Rao E. Prevalence of Hypertension among Urban Adult Population (25-64 years) of Nellore, India. Int $J$ Res Dev Health 2013;1(2):42-9.

17. Tee SR, Teoh XY, Aiman W, Aiful A, Har CSY, Tan ZF, et al. The prevalence of hypertension and its associated risk factors in two rural communities in Penang, Malaysia. IeJSME 2010; $2: 27-40$

18. Doğan N, Toprak D, Demir S. Hypertension prevalence and risk factors among adult population in Afyonkarahisar region: a crosssectional research. Anatolian J Cardiol 2012;12 (1):47-52

19. Saeed KMI. Prevalence of hypertension and associated factors in Jalalabad City, Nangarhar Province, Afghanistan. Cent Asian J Global Health 2015;4(1).

20. Aung HA. Assessment of modifiable risk factors of hypertension among military community at Mingalardon Cantonment, Yangon in 2015. [thesis]. Master of Medical Science (Health Care Management). Defence Services Medical Academy, Mingladon, Myanmar, 2015.

21. Kyaw ZH. Prevalence, awareness, treatment seeking patterns and risk factors of hypertension among the middle aged people in Bago Township. [thesis]. Master of Public Health. Defence Services Medical Academy, Mingladon, Myanmar, 2013.

22. Zafar SN, Gowani SA, Irani FA, Ishaq M. Awareness of the risk factors, presenting features and complications of hypertension amongst hypertensives and normotensives. JPMA 2008; 58(12):711-5. 